\title{
Field study on effect of hormonal protocol on treatment of postpartum anoestrus in water buffaloes of semi-arid region of Uttar Pradesh
}

\author{
Deep Narayan Singh ${ }^{1}$, Amit Singh $^{2}$, Jai Singh ${ }^{1}$ and Sarvajeet Yadav ${ }^{3}$
}

Received: 14 February 2021 / Accepted: 25 June 2021 / Published online: 07 September 2021

(C) Indian Dairy Association (India) 2021

\begin{abstract}
Water Buffalo (Bubalus bubalis) is one of the premier productive animal and a major contributor to milk, meat, skin and draught power in our country. It is a better dairy animal in comparison to cattle in terms of better feed (roughage) conversion efficiency, greater resistance to diseases and higher milk fat percentage. But anoestrus is the most important cause of poor reproductive performance in buffaloes both in field condition as well as in organized farm. The percentage of anoestrus is more in rural areas mainly due to malnutrition, lack of scientific knowledge and improper management practices causing huge economic losses to the farmers. Thus this study was conducted to test the effectiveness of GPG protocols in farmers field for treating anoestrus in buffaloes with PGF2 $\alpha$ or GnRH protocol under the field conditions. A total of 36 animals were selected from different affected villages of Mathura district with good body condition score (BCS $>2.5$ ), parity of two or above, healthy reproductive organs and history of minimum 6 months anoestrus problems after reaching the age of breeding or after calving or the last breeding were selected. The treated animals were examined by per-rectal method. Among 36 treated buffaloes, 13 were found pregnant $(36.11 \%)$ and another 9 buffaloes had become cyclic with success rate of treatment was $61.11 \%$.
\end{abstract}

Keywords: Anoestrus, BCS, GnRH, PGF2 $\alpha$, Semi-arid zone

\footnotetext{
${ }^{1}$ Department of Livestock Production Management, ${ }^{2}$ Department of Veterinary \& Animal Husbandry Extension, ${ }^{3}$ Directorate of Extension College of Veterinary Science \& Animal Husbandry U.P. Pt. Deen Dayal Upadhyaya Pashu Chikitsa Vigyan Vishwavidyalaya Evam Go-Anusandhan Sansthan, Mathura-281001, Uttar Pradesh

Amit Singh $(\bowtie)$

Department of Veterinary \& Animal Husbandry Extension

U.P. Pt. Deen Dayal Upadhyaya Pashu Chikitsa Vigyan Vishwavidyalaya Evam Go-Anusandhan Sansthan, Mathura-281001, Uttar Pradesh

Email: dr25amitsingh@gmail.com
}

Water Buffalo (Bubalus bubalis) is one of the premier dairy animals of India as it contributes over 49.00 per cent of the total milk produced in the country (DAHD\& F, 2019-20). In India, buffaloes are mainly reared by small-livestock holders in subsistence or semi-commercial farms as they produce large quantity of milk with high fat and Solid Non Fat (SNF) content but also plays a significant role as a draught and meat animal. The good feed conversion efficiency of buffaloes and relatively low maintenance requirements are attributes which make them ideal in low-input, low-cost production systems. At present our country is having 109.85 million (DAHD\&F, 2019) buffalo which has increases by $1.1 \%$ over previous livestock census (2012). Our country is also having a good quality buffalo germplasm with many productive dairy breed. Although buffaloes have very acceptable productive potential but certain reproductive problems are also associated like silent heat coupled with late maturity, long postpartum anoestrus intervals, poor expression of oestrus, poor conception rates (CR) and long calving intervals which restricts their reproductive performance consequently with altering the productivity (Singh et al. 2015). The major problems faced by buffalo breeders includes poor reproductive efficiency $v i z$. Anoestrus, repeat breeding, silent heat and prolonged intercalving intervals (Barile, 2005 and Perera, 2008). Buffaloes are considered as difficult breeder due to several reproductive problems such as delayed puberty, silent oestrus, summer anoestrus, post-partum anoestrus and repeat breeding leading to huge economic losses to farmers with fluctuation in milk production throughout the year. Clinical examinations had revealed that anoestrus is one of the major problems in buffaloes (Ahmed, 2006 and Patel et al. 2007). Anoestrus is one of the most commonly occurring reproductive problems in cattle and buffalo in India, affecting livestock productivity and profitability to a great extent (Yadav et al. 2018). It is defined as absence of periodic manifestation of oestrus, with the absence of palpable follicular or luteal structures (smooth ovaries) or absence of normal physiological signs of oestrus associated with a corpus luteum (physiological anoestrus). Inactive or non-functional ovary is one of the most important causes of anoestrus in buffaloes. Anoestrus is one of the most commonly occurring reproductive disorders in buffaloes. The problem is more severe in sub urban and rural areas especially semi-arid 


\section{Treatment protocol}

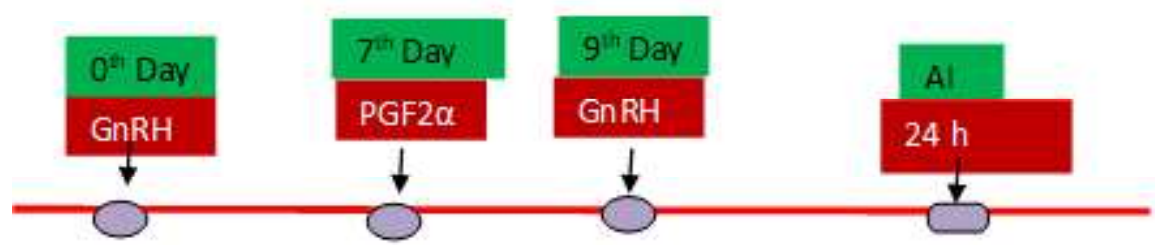

Table1 Estrus response in postpartum anoestrus buffaloes

\begin{tabular}{lllll}
\hline S. No. & Treatment protocol & $\begin{array}{l}\text { Number of } \\
\text { animal treated }\end{array}$ & $\begin{array}{l}\text { Number of buffalo } \\
\text { responded (estrus) }\end{array}$ & Percent response \\
\hline 1. & GPG protocol & 36 & 22 & $61.11 \%$ \\
\hline
\end{tabular}

Table 2 Onset of estrus duration in Postpartum anoestrus buffalo

\begin{tabular}{llllll}
\hline S. No. & $\begin{array}{l}\text { Treatment } \\
\text { protocol }\end{array}$ & $\begin{array}{l}\text { Number of } \\
\text { animal treated }\end{array}$ & $\begin{array}{l}\text { Average time } \\
\text { required for onset } \\
\text { of oestrus }\end{array}$ & $\begin{array}{l}\text { Duration of } \\
\text { Oestrus }\end{array}$ & $\begin{array}{l}\text { First service } \\
\text { Conception rate } \\
(\%)\end{array}$ \\
\hline 1. & GPG protocol & 36 & $67.80 \pm 1.44 \mathrm{~h}$. & $23.85 \pm 0.54 \mathrm{hrs}$ & $36.11 \%$ \\
\hline
\end{tabular}

region of the country. Regular reproductive examination of buffaloes at an appropriate interval is practically difficult in rural areas due to constraints of expenses and qualified veterinary service in rural areas (Dhakad et al. 2018). Anoestrus buffaloes are conventionally treated with vitamin-mineral mixture supplements with the variable effects. Several methods of oestrus and ovulation induction using hormonal protocol have been recently developed in buffaloes for treating anoestrus and improving their reproductive efficiency. Thus to test the effectiveness of GPG protocols under the field conditions the present study was planned and analyzed.

The present study was undertaken purposively in the state of Uttar Pradesh which is one of highest producer of milk and possesses about 33.0 million buffaloes in country (DAHD\&F, 2019). The study was carried out purposively in the Mathura district which comes under the semi-arid region of the state. The district suffers from chronic saline water problem along with problem of erratic rainfall so reproductive problems in livestock species are common. A total of 36 animals were selected with good body condition score (BCS $>2.5$ ), parity of two or above, healthy reproductive organs and history of minimum 6 months anoestrus problems after reaching the age of breeding or after calving or the last breeding. Deworming was done by fenbendazole with ivermectin and mineral mixtures were provided as a feed supplement in the ration of the selected animals @,50 gram per day for 15 days before the starting of treatment. The post partum anoestrus buffaloes (anoestrus buffaloes) received Ovsynch protocol with administrating $5 \mathrm{ml}$ of $\mathrm{GnRH}$ analogue (Receptal; $\mathrm{M} / \mathrm{s}$ Intervet International) on any day by intramuscular route; followed by $2.5 \mathrm{ml}$ of Estrumet (M/s Upjohn, UK) on seventh days and second GnRH injection (Receptal $5 \mathrm{ml}$ ) $48 \mathrm{hrs}$ after Estrumet administration. All animals were subjected to fixed time artificial insemination (AI) after 18 to 24 hours post second Receptal administration. Estrus detection and intensity of oestrus was analyzed by visual observation and per rectal examination.

There are many factors causing anoestrus problem in buffalo like poor nutritional status, negative energy balance, parasitic infestation, hormonal imbalance, Uterine pathology (Purohit, 2014), (Gilbert, 2011). Out of 36 anoestrus buffaloes each subjected to GPG protocols $61.11 \%$ buffaloes exhibited behavioural estrus (Table 1) with prominent to moderate signs within mean intervals of $67.80 \pm 1.44 \mathrm{~h}$. The present findings of estrus exhibition are in accordance with Hirole et al. (2018). However, our findings differ with worker like Bhoraniya et al. (2012), Ramkrishnan et al. (2012) and Deshmukh et al. (2017) who reported $100 \%$ oestrus response after GPG treatment.

Time required for onset of estrus: The average time required for onset of estrus after last $\mathrm{PGF}_{2}$ ? injection was $67.80 \pm 1.44 \mathrm{~h}$. The result observed in present study for mean time required for onset of induced estrus are in agreement with findings of Hirole et al. (2018) who recorded the time required for onset of induced estrus with Ovsynch protocol as $53.20 \pm 1.8 \mathrm{hrs}$ and $54.60 \pm 2.44$ by Ratnaparkhi et al. (2020). The mean value of duration of estrus detection was $23.85 \pm 0.54 \mathrm{hrs}$. Similarly the study of Deshmukh et al. (2017) reported the duration of estrus observed as $21.42 \pm 0.57$ hrs. The conception rate in present study among 36 animals were 
observed as 36.11 percent with GPG protocol and another 9 buffaloes had become cyclic $(25 \%)$ thus providing a overall success rate of 61.11 percent in first trial.

\section{Conclusion}

Postpartum anoestrus in buffalo is a very serious reproductive problem affecting $30-40 \%$ of the total buffalo population and it causes huge economic losses to our livestock owners. The application of PGF $2 \alpha$ or GnRH protocol (ovsynch protocol) for fertility improvement in anoestrus buffaloes is a useful biotechnique to enhance farmers' incomes in terms of productivity and profitability. Hence, this protocol is very effective for treatment of postpartum anoestrus in water buffaloes of semiarid region of Uttar Pradesh.

\section{Acknowledgements}

Author is highly thankful to Vice Chancellor, DUVASU and UPCAR for providing financial support and necessary facilities for carrying out this research.

\section{References}

Ahmed K (2006) Inidence of various reproductive disorders in swamp buffaloes of Assam. Indian J Anim Reprod 12:49

Barile VL (2005) Improving reproductive efficiency in female buffaloes. Livest Prod Sci 92: 183-194

Bhoraniya BL, Dhami AJ, Ankita K (2012) Influence of estrus synchronization protocols on fertility plasma progesterone and biochemical constituents in Kankrej cows. Indian J. Anim.Reprod $33: 14-18$

DAHD\&F (2019) Department of Animal Husbandry, Dairying \& Fisheries Ministry of Agriculture \& Farmers Welfare Government of India. Annual report
Deshmukh SG, Sajid Ali, S Bankar, Patil MS (2017) Effect of dietary supplementation of crushed flaxseed and soyabean oil on estrus attributes in postpartum cows. Int J Sci Environ Technol 6: 34513459

Dhakar KK, Singh Yajuvendra, Singh Kaushalendra, Raja TV, Singh DN, Sirohi R (2018) Physio-haematological and biochemical changes in dairy cows during different stages of estrus. Indian J Anim Prod Manage 34:50-55

Gilbert RO (2011) The effects of endometritis on the establishment of pregnancy in cattle. Reprod Fertil Dev 24: 252-257

Hirole PD, Deshmukh SG, Ingawale MV, Kuralkar SV, Thorat MG, Ratnaparkhi AR, Godbole PV (2018) Comparative efficacy of two different synchronization protocols in postpartum dairy cows. Int $\mathrm{J}$ Livest Res 8: 283-290

Patel SB, Hadiya KK, Chavan DB (2007) Incidence of reproductive disorders in cattle and buffaloes in Kaira district of Gujrat. Indian J Field Vet 3:15-17

Perera B M (2008) Reproduction in domestic buffalo. Reprod Domest Anim 43:200-206

Purohit GN (2014) Ovarian and oviductal pathologies in the buffalo: occurrence, diagnosis and therapeutic approaches. Asian Pac J Reprod $3: 156-168$

Ramkrishnan A, Dhami AJ, Naikoo M, Parmar BC, Divekar BS (2012) Estrus induction and fertility response in postpartum anestrus Gir cows. Indian J Anim Reprod 33:37-42

Ratnaparkhi AR, Deshmukh SG, Birade HS, Kale VB, Harkal SB, Jadhao AD (2020) Comparative efficacy of synchronization protocols for improving fertility in postpartum crossbred dairy cows. Haryana Vet 59: 23-26

Singh DN, Singh Y, Sirohi R, Kumar Ajay, Shukla PK (2015) Concept note on Management practices to improve performance of buffaloes in India. Indian J Agric Business 1:115-120

Yadav Sarvajeet, Singh Amit, Singh Deep Narayan, Singh Jai (2018) Factors influencing adoption behaviour of the dairy farmers in semi-arid region of Uttar Pradesh. Ruminant Sci 7:301-303 